\title{
LETRAMENTO NA ERA DA INFORMAÇÃO: A QUESTÃO DA LEITURA EM MEIO DIGITAL NA PESQUISA CIENTÍFICA UNIVERSITÁRIA
}

Cristina Vergnano Junger

(Universidade do Estado do Rio de Janeiro)

RESUMO

Neste artigo trazemos reflexões de caráter teórico sobre a prática letrada da revisão bibliográfica por parte de alunos universitários, entendida como uma atividade de leitura. Nosso foco volta-se para as implicações do uso da internet como fonte de pesquisa e as relações que podem ser estabelecidas para o desenvolvimento do nível de letramento neste contexto particular. Nesse sentido, oferecemos alguns parâmetros para o desenvolvimento de tal prática letrada. Apoiamo-nos nos conceitos de letramento de Cerutti-Rizzatti, Kleiman, Gasque e Soares, rejeitando, no entanto, a pluralização do termo. Para a questão da leitura, adotamos uma perspectiva multidirecional, segundo Vergnano-Junger. A título de problematização, defendemos que as práticas letradas universitárias oferecem desafios aos alunos e demandam aprendizagem específica que precisa ser implementada nos currículos. A realização de pesquisas e revisão bibliográfica, por exemplo, têm na internet uma importante fonte de recursos. Mas, devido às características do meio virtual, demanda capacidades de seleção, comparação, organização e criticidade que se somam às habilidades, estratégias e conhecimentos já requeridos para a atividade nos suportes impressos. Reconhecemos, porém, que nem sempre a preocupação sistemática com os aspectos da leitura de revisão bibliográfica está presente na formação acadêmica e que, no que se refere à internet, tal ausência é mais patente. Concluímos que parte da questão pode relacionar-se ao momento de transição em que nos encontramos em nossa relação com as tecnologias da informação e comunicação (TICs) e as práticas que instauram. PALAVRAS-CHAVE: letramento; revisão bibliográfica; internet 


\section{A leitura para pesquisa e sua relação com o letramento: uma proposta de reflexão}

0 conceito de letramento é relativamente recente em termos históricos (GASQUE, 2010). Segundo Kleiman (2004) e Gasque (2010), ao apresentar uma breve trajetória histórica sobre o tema, o termo teria sido utilizado em nosso país, pela primeira vez, por Mary Kato em 1986. No Brasil, portanto, ele pode ser assumido como um neologismo, como nos propõe Cerutti-Rizzatti (2012).

Conceituar letramento é uma tarefa complexa, uma vez que coexistem diferentes orientações teóricas e ideológicas que levam a posicionamentos distintos e, inclusive, em certa medida, antagônicos. Kleiman (2004) expõe tal dicotomia na caracterização de dois modelos de letramento: o autônomo e o ideológico. No primeiro caso, "a escrita seria [...] um produto completo em si mesmo, que não estaria preso ao contexto de sua produção para ser interpretado" (KLEIMAN, 2004, p. 22). No segundo, ao contrário, embora não propondo "uma negação de resultados específicos dos estudos realizados na concepção autônoma” (KLEIMAN, 2004, p.39), destaca o seu caráter intrinsicamente cultural e de ligação a estruturas sociais de poder. Ou seja, "as práticas de letramento mudam segundo o contexto" (KLEIMAN, 2004, p. 39).

Concordamos que o aspecto sociocultural está no cerne das discussões sobre o que é o letramento. De tal forma, não é possível discutir práticas letradas sem pensar nos contextos em que estas ocorrem, nos seus sujeitos e na interação entre estes e o seu entorno. No entanto, destacamos e seguimos o alerta de Cerutti-Rizzatti (2012) ao argumentar que, apesar dessa ligação (e mesmo devido a ela), tem havido uma ampliação excessiva do conceito. Isso tem levado, inclusive, à sua pluralização (letramentos, multiletramentos, letramento digital etc.), aspecto com o qual discordamos, em consonância com CeruttiRizatti (2012). Pese ao fato de que não podemos excluir de nossas discussões o caráter sociocultural do conceito, com tudo o que isso significa, "letramento necessariamente implica vinculação com o signo verbal escrito, condição para que se fale de práticas de letramento ou de eventos de letramento" (CERUTTI-RIZZATTI, 2012, p. 293).

Soares (2002), por sua vez, parte da vertente das práticas de leitura e escrita em sociedade, para ampliar o conceito. A autora associa, então, letramento ao "estado ou condição de indivíduos ou 
de grupos sociais de sociedades letradas que exercem efetivamente as práticas sociais de leitura e de escrita, participam competentemente de eventos de letramento" (SOARES, 2002, p.145). As implicações de seu posicionamento incluem a constatação de que esses indivíduos e grupos desenvolvem os requisitos necessários (habilidades e atitudes) à atuação competente nas mais variadas situações mediadas pela palavra escrita, na interação com os demais e com o mundo circundante.

Atualmente, como já pontuamos, vemos nos trabalhos de diferentes autores, expressões como letramentos e/ou multiletramentos. Também se apresentam diferentes modalidades de letramento identificadas por adjetivações do termo (letramento digital, ciberletramento, letramentos múltiplos, letramento informacional etc.), muitas vezes motivados pela relação com a mediação informática (CASTELA, 2008. ROJO, 2009. GASQUE, 2010). No entanto, seguindo a linha de raciocínio de Cerutti-Rizzatti (2012) e o conceito expresso por Soares (2002), reiteramos que, em nossas pesquisas, adotamos "letramento" no singular. Entendemos o termo como uma ideia quase coletiva, que abarca a multiplicidade de ações mediadas pela palavra escrita e o estado dos indivíduos nesse contexto. Isso nos leva a considerar cada especificidade (digital, informacional, visual etc.) não como um entre vários letramentos, mas como parte de um continuum (cf. GASQUE, 2010). Este ocorre num processo social, cultural, linguístico e cognitivo que se modifica e enriquece ao longo da vida dos indivíduos, membros de sociedades letradas. Nesse sentido, nos parece mais lícito falar em práticas ou eventos de letramento, quando se pretende pontuar as diferentes faces do fenômeno.

Mas, que pontes podemos estabelecer entre este conceito e as práticas letradas universitárias, em especial aquela relacionada à pesquisa de revisão teórica? Kleiman, ao referir-se à visão de letramento como uma metodologia para ensinar leitura e escrita, lembra-nos que, na academia, isso "acarreta uma compreensão ampla da língua escrita, de modo a incluir as práticas de ler e escrever da vida social" (KLEIMAN, 2010, p. 379). A autora abordava o tema com o foco na tensão alfabetização/letramento. No entanto, assumindo a formação universitária como parte do ensino formal e sistemático, ligada, portanto, à tradição de valorização da escrita segundo os parâmetros dos meios escolares, defendemos que a colocação é pertinente para este caso em particular. 
Nesse sentido, propomos lançar no presente artigo, um olhar para uma das práticas sociais do mundo universitário. Trata-se da construção e circulação dos saberes pela interação entre aqueles que os produzem, com mediação da palavra escrita.

Isso significaria, num primeiro momento, enfocar ambos: leitura e escrita. Porém, dada a nossa trajetória de investigação, a questão que levantamos se detém no aspecto da leitura. Mais concretamente, abordamos as práticas de revisão teórica, em busca da determinação do estado da arte de temas em estudo por alunos universitários. Para realizar tal tarefa, começamos por uma breve reflexão sobre o contexto atual da era digital, em especial no que se refere ao status da informação e ao papel do sistema escolar. Seguimos com considerações sobre a leitura mediada pelas tecnologias da informação e comunicação (TICs), para, por fim, abordar o tema específico da atividade de revisão teórica no meio universitário. Além das discussões de cunho teórico, propomos alguns problemas e caminhos de atuação, em especial vinculados à formação do aluno universitário.

\section{Panorama social e escolar: o antigo, o novo e o letramento na era digital}

Começamos a refletir neste tópico sobre as relações entre sociedade, escola e letramento a partir da proposta de Mendoza (2011) de um panorama sintético de mudanças socioculturais ao longo do tempo. Utilizando conceitos de cultura residual, hegemônica e emergente, o autor reflete sobre o momento no qual nos encontramos - o da cibercultura -, confrontando-o à cultura letrada (entre os Séculos IV a.C. e XIX) e à industrial (Séculos XIX e XX).

Segundo o exposto pelo autor (MEND0ZA, 2011), a cultura letrada corresponde à valorização da palavra escrita, da conceituação, do elevado e culto em oposição ao baixo e inculto. Ou seja, não se refere, especifica e diretamente, ao que vínhamos abordando como sociedades letradas: aquelas em que se atua por mediação da palavra escrita. Marca, ao contrário, a supremacia de determinadas formas escritas, e, por extensão, de seus usuários, sobre outras.

Com a revolução industrial e o surgimento dos meios de comunicação de massa, a cultura letrada perde seu lugar hegemônico, cedendo-o à emergente cultura industrial. Esta se caracteriza por um processo cultural de natureza diversa, no qual o veículo se enfatiza, 
bem como o aspecto quantitativo, aumentando-se tanto público quanto o "volume cultural" difundido (MENDOZA, 2011, p. 87). Nesse contexto, a presença/permanência da cultura letrada é tomada por muitos como "formas de resistência" (MENDOZA, 2011, p. 88).

A cibercultura é hoje o panorama emergente. As tensões anteriores entre manifestações culturais de alto ou de baixo valor cedem lugar a uma era de transição e encruzilhada entre diferentes registros culturais. No dizer de Mendoza (2011, p. 90-91), “cultura letrada, cultura industrial y cibercultura participan de una emulsión

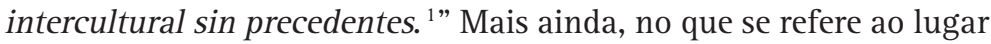
da internet, esta "emerge [...] como nuevas pistas de circulación de la cultura industrial [...]; pero también como soporte de recontextualización de la cultura letrada [...]" MENDOZA, 2011p. 91). Sendo assim, por exemplo, a cultura industrial manifesta-se nos recursos multimidiáticos, enquanto a letrada, na riqueza e variedade de bibliotecas virtuais e periódicos acadêmicos on-line.

Este momento em que vivemos está, sem sombra de dúvidas, tomado mais e mais pelo digital. Novas formas de fazer negócio, de contatar pessoas, de compartilhar coisas (fotos, ideias, informação) e de interagir surgem a cada dia, impulsionadas pelos avanços tecnológicos e o que estes permitem/favorecem. Podemos constatá-lo na vida cotidiana em sociedade. 0 mesmo, no entanto, não ocorre no sistema escolar com o igual sucesso. Essa tensão se manifesta tanto pelo desinteresse dos jovens pelo que a escola, tradicionalmente lugar de transmissão de saber enciclopédico, oferece, quanto pela angústia de muitos professores ao terem que lidar com essa emergente tecnologia em seu trabalho (BACHER, 2009). E, como pontua Lavid (2005), a simples inserção das tecnologias não garante as transformações necessárias nos métodos tradicionais de ensino, centrados em memorização, numa aprendizagem descontextualizada, ou ênfase conteudista.

A nossa é a era da informação. Vivemos em uma sociedade na qual a informação é um direito, um bem social (BACHER, 2009). Isso porque, por meio dela, podemos transformar o mundo e atuar nele com maior segurança e profundidade. A internet permite compartilhar informações e conhecimentos como nunca. Temos acesso a uma infinitamente virtual rede de conteúdos, ao alcance de um clic (CASSANY, 2012). E esse acesso, embora possa ser considerado um “estruturador das democracias” (BACHER, 2009, p. 46), não chega a 
ocorrer como tal sem que haja sobre o nosso olhar um processo educativo. Como nos lembra Cassany (2012), há uma série de conhecimentos e habilidades envolvidos na questão. Dentre eles, destaco e comento apenas aqueles relacionados mais diretamente ao processo leitor: (a) de informática, para viabilizar o uso da tecnologia; (b) de biblioteconomia, a fim de saber usar os mecanismos de busca eficazmente; (c) de análise do discurso, para procurar entender ideologias, intencionalidades e aspectos culturais embutidos nas escolhas da língua; (d) de imagem e (e) de direitos de propriedade (CASSANY, 2012, p. 38-39).

Muito frequentemente, no entanto, como nos lembra Bacher (2009), não chegamos a alcançar tais requisitos. Ao menos, não da forma mais plena e crítica como deveríamos dominá-los. Ainda que tenhamos garantido o acesso à informação, isso não significa que conseguiremos selecioná-la e utilizá-la criticamente. Este é, na visão da autora, a qual compartilhamos, o papel preponderante do sistema escolar hoje. Ou seja, contribuir para que possamos organizar o fluxo extenso e por vezes caótico da informação que temos à nossa disposição (BACHER, 2009). Cassany (2012, p. 40) nos traz a “metáfora da brecha" que ilustra bem o problema em pauta. Por um lado, há uma brecha representada pela ausência de acesso aos meios tecnológicos, ainda não tão democráticos e equânimes. Por outro, há outra brecha, igualmente responsável pelas desigualdades e empoderamento de apenas alguns segmentos da sociedade: aquela representada pela falta de formação adequada para as práticas mediadas pela palavra escrita em meio digital. Se a primeira já pode, em certa medida, ser minimizada pelo compartilhamento de recursos via escola, a segunda, seguramente, tem no sistema educacional formal (incluída a universidade), um espaço privilegiado para seu combate.

3. Leitura mediada pelas tecnologias da informação e comunicação: uma perspectiva sociocognitiva

Como foi mostrado pela discussão desenvolvida até aqui, a leitura ${ }^{3}$ constitui uma das práticas de letramento. Trata-se de uma atividade social e também cognitiva, complexa, que, como tal, precisa ser ensinada/aprendida.

Desde a metade do Século XX, observamos estudiosos ocupa- 
dos em descrever o processo leitor, como nos informa Kleiman (1996). Seguindo a exposição da autora, constatamos que foram propostos três diferentes modelos de descrição da atividade leitora: ascendente, descendente e (sócio)interativo. Cada caso foi estabelecido em função do elemento-chave considerado com centralidade na leitura - texto, leitor ou a interação entre ambos, respectivamente.

Nos dois primeiros, o fluxo da informação se concentra numa única direção. No ascendente, segue do texto para o leitor, cuja função, neste caso, é prioritariamente decodificadora. No descendente, percorre trajeto inverso, passando o leitor ao papel ativo de atribuir os sentidos. Em nossos estudos, concluímos que, embora opostos enquanto concepção, na prática apontam para um mesmo formato de comportamento: o unidirecional (VERGNANO-JUNGER, 2015). Isso significa que apenas um dos elementos é tomado como foco de cada vez, isoladamente, num movimento que considera o fluxo da informação numa "mão única".

Ambas as propostas, como já havia ocorrido separadamente nas análises e avaliações dos modelos ascendente e descendente durante os avanços nos estudos, caracterizam-se como insuficientes para contemplar a complexidade do fenômeno. 0 modelo (sócio)interativo, ao contrário, coloca seu foco em ambos os sentidos do fluxo informacional ao mesmo tempo (KLEIMAN, 1996; NUNES, 2005.). Ou seja, reconhece que tanto o texto quanto o leitor e sua bagagem (incluídos aspectos sociais) contribuem para que os significados sejam negociados e os sentidos construídos. Tal modelo associa, portanto, os constituintes da composição textual - seus elementos linguísticos, sua coesão, seus conteúdos - aos aspectos cognitivos do leitor - seus conhecimentos, estratégias, memória, aprendizado.

A partir de nossas pesquisas, além do que o modelo sociointerativo propõe considerando texto e leitor, associamos tudo mais que pode ser levado para o processo de ler, proveniente dos contextos social, histórico, cultural, discursivo, de gênero. Todos esses componentes pertencem tanto à esfera do leitor quanto a do autor e da(s) sociedade(s) em que se inserem, criando uma teia de informações. Devido a essa multiplicidades de trajetórias que o fluxo da informação pode percorrer, de suas diversas fontes em diálogo, é que passamos a considerar a leitura sob uma perspectiva multidirecional (VERGNANO-JUNGER, 2015). Assumimos, também, que esta é a melhor opção teórico-metodológica para discutir o processo leitor nos 
dias de hoje. Em especial se considerarmos a rede de conexões que caracteriza a comunicação e a apresentação da informação num contexto digital.

Nossa posição defende o caráter de atividade social da leitura, ressaltando a importância de lançar-lhe um olhar, em termos de ensino-aprendizagem principalmente (posto que na vida extraescolar isso já ocorre de modo natural), contextualizado. Nesse sentido, cada situação leva a um comportamento leitor próprio e exige, em contrapartida, conhecimentos, estratégias, conexões e atitudes a ela pertinentes. Por isso, tomamos como claro que não se podem ignorar as possibilidades variadas de compreensão de um mesmo material. Tal pressuposto se apoia nas múltiplas variáveis que enriquecem (ou podem fazê-lo) a leitura de diferentes leitores, em distintos tempos e espaços. No entanto, mantemos a ressalva de que tais possibilidades jamais são infinitas, dado que seus próprios elementos constituintes, incluído o texto em si e seu gênero, podem atuar como elementos coercivos.

Em termos cognitivos, a atividade leitora tem igualmente a condição de incrementar-se, o que em geral ocorre por meio de mais leituras, com critérios elevados de busca e construção de coerência (PERFETTI; LANDI; OAKHILL, 2013). Sempre podemos estar abertos a aprender algo novo, incorporar modelos/esquemas, rotinas e estratégias à nossa bagagem procedimental e enciclopédica. À medida em que nos colocamos em contato com novas situações e materiais de leitura, temos a oportunidade de aplicar e aperfeiçoar estratégias diversas, como as dos processos superiores de compreensão: monitoramento e inferências (PERFETTI; LANDI; OAKHILL, 2013). Tal conduta é desejável de modo especial quando pensamos na complexidade de determinados textos e/ou situações de leitura, como, por exemplo, no caso do ambiente universitário.

Quando pensamos no contexto específico das tecnologias da informação e comunicação (TICs) e em nossa sociedade da informação, nos deparamos com textos construídos de forma hipertextual e multimodal. Eles se organizam numa rede não centralizada ou hierarquizada, segundo a oferta de seus autores ou criadores de páginas. Seu acesso, porém, depende majoritariamente das opções dos leitores (CASSANY, 2012. VERGNANO-JUNGER, 2015). Estes, efetivamente, atualizam os textos e compõem verdadeiros "livros", frutos de suas escolhas, materializando seus caminhos de leitura em produtos muitas vezes fluidos. 
A hipertextualidade não é uma prerrogativa exclusiva dos textos virtuais. Aparece nas notas de rodapé ou nas referências bibliográficas dos textos impressos, entre outros. 0 mesmo podemos dizer da multimodalidade, já que diferentes semioses podem estar presentes em textos impressos. As mais comuns são as ilustrações/imagens, mas, não raro, encontramos em livros infantis, por exemplo, texturas diversas e mesmo sons. No entanto, a tecnologia informática potencializa ambos os aspectos, torna-os constitutivos dos textos eminentemente digitais e faz os acessos mais rápidos e práticos. De igual maneira, favorece tanto sua efemeridade, quanto os problemas relacionados à autoria e/ou exatidão de conteúdos. Tais aspectos precisam ser levados em conta no momento da leitura e fazem parte do processo de desenvolvimento da criticidade e capacidade de seleção e uso, ao qual já nos referimos antes (CASSANY, 20102. VERGNANOJUNGER, 2015).

Somamos a todas essas considerações, por fim, a questão dos gêneros textuais, com base na proposta apresentada por VergnanoJunger (2015) ${ }^{4}$. Adotamos uma caracterização de gênero baseada em quatro pilares: sua função comunicativa, sua forma (ou estrutura), seu conteúdo e seu suporte. Esses podem ser analisados à luz de três níveis: o da produção, o da recepção e o da contextualização. 0 primeiro deles tem aqui menor impacto, já que o tema em foco é a leitura. No entanto, consideramos que, numa perspectiva sociointerativa e multidirecional, ocorre um constante diálogo com o texto e, por extensão, com seu autor, e que este, ao escrever, pressupõe seus interlocutores. Portanto, o nível da produção não pode ser totalmente excluído das análises dos gêneros nas instâncias leitoras. 0 nível da recepção reúne todos os aspectos que podem ser elencados durante a atividade do leitor. Ou seja, contempla sua bagagem de conhecimentos, as estratégias que aciona, as negociações que realiza, os caminhos que escolhe percorrer, todos os diálogos e conexões que vai construindo (ou, potencialmente, pode construir) durante sua leitura. Finalmente, a contextualização permite lançar um olhar sintetizador que engloba todos os níveis e pilares. Enlaça-os aos aspectos sociais, históricos, culturais, conjunturais, do espaço e do tempo em que se inserem todos os elementos e atores do processo. Assim, os gêneros textuais, enquanto "categoria cultural e esquema cognitivo" (MARCUSCHI, 2008, p.149), ganham relevância no contexto de desenvolvimento do processo leitor e do letramento, demandando aná- 
lise e consideração.

Ao considerar a realidade atual e o intenso envolvimento com as TICs, admitimos que nosso atuar no mundo por meio da língua escrita acaba, por força das circunstâncias, gerando novas necessidades e instaurando novos gêneros ou formas modificadas de antigos. Associadas a isso, vêm as diferentes formas de agir, as habilidades e conhecimentos demandados pelo suporte e as possibilidades que este instaura (cf. CASSANY, 2012).

\section{Revisão teórica mediada pela internet: uma prática leitora universitária com demandas específicas}

A conceituação de letramento que vimos trazendo ao longo deste artigo envolve tanto as práticas sociais mediadas pela palavra escrita, quanto o status dos sujeitos que vivem e atuam nessa sociedade letrada. Os estudantes universitários, de graduação e/ou pós-graduação, estão inseridos nessa realidade e são indivíduos que participam de diferentes práticas de letramento cotidianamente. Sem dúvida, sabem ler e escrever.

O contexto universitário, contudo, apresenta-lhes situações específicas de interação por meio da palavra escrita que antes, provavelmente, lhes eram desconhecidas e que fogem às práticas mais cotidianas (CUBO DE SEVERINO; CASTRO DE CASTILLO, 2005). Sob o rótulo de discurso acadêmico-científico podemos incluir vários gêneros textuais (ou subgêneros). Eles compartilham uma série de características comuns, como escolhas lexicais e estruturais da língua (uso de passiva, ou da impessoalidade, por exemplo), mas também possuem especificidades segundo o papel que ocupam no contexto acadêmico (CUBO DE SEVERINO; CASTRO DE CASTILLO, 2005). Aprender a escrevê-los e a lê-los, de modo a alcançar os objetivos traçados para as diferentes práticas de letramento desse meio, costuma representar um desafio para a maioria. É nesse sentido que o cuidado formativo dos cursos universitários deve ser incrementado.

Com base na proposta teórico-metodológica para a classificação dos gêneros textuais que citamos anteriormente (cf. VERGNANOJUNGER, 2015), começamos desenvolvendo um breve panorama dos gêneros do âmbito acadêmico-científico. Segundo o pilar da função comunicativa, podemos constatar que os textos desses gêneros compartilham a função primária de informar sobre pesquisas, suas 
metodologias e resultados. Mas esse dar a conhecer o que está sendo construído academicamente pode desdobrar-se, segundo o contexto em que ocorra. Assim, se se trata de artigos científicos, produzidos por cientistas para uma interlocução com seus pares, podemos somar a tal função a de delimitação das autorias, ou seja, quem tem a autoridade sobre determinadas descobertas. Outros, como monografias, dissertações e teses, acumulam a função de avaliação.

No que se refere ao pilar da forma, temos certa padronização quanto ao uso de uma linguagem mais objetiva, que busca eliminar ambiguidades, com presença massiva de termos técnicos, abreviaturas e siglas (GUTIÉRREZ RODILLA, 2005). Sua estrutura também costuma seguir padrões previamente estabelecidos. De maneira geral, comporta uma introdução, um desenvolvimento e uma conclusão. No entanto, essa estrutura composicional pode variar segundo o gênero, como, por exemplo, a falta de conclusão num projeto científico.

0 pilar do conteúdo depende de vários fatores, muitos dos quais observáveis com o olhar do nível da contextualização. Por exemplo, a área do conhecimento, a temática, o grau de formação do autor na hierarquia acadêmica, a situação comunicativa dos envolvidos e o próprio gênero em questão podem modular o padrão mais ou menos geral e estável dos conteúdos dos textos. Neste modelo geral se incluem, frequentemente, revisão teórica, proposta metodológica, apresentação, análise e discussão de dados, sempre enfocando a temática e o problema determinados segundo o caso. A profundidade e abrangência dos elementos se ajustam ao propósito comunicativo de cada gênero. Assim, o resumo, por exemplo, tratará esses aspectos de maneira mais superficial e concisa do que o artigo.

Embora todos os pilares tenham sua relevância na determinação e caracterização do gênero, damos um destaque ao suporte, em função de nossos objetivos e foco deste trabalho. Os diferentes gêneros textuais do meio acadêmico tradicionalmente se apresentavam em suporte impresso (revistas, livros, anais), ou oralmente (conferências, aulas magnas, defesas de trabalhos finais). Com o advento da internet e sua popularização crescente, um novo espaço se abre ao armazenamento, apresentação e distribuição desses textos: o virtual. Surgem as revistas virtuais, os livros digitais, os portais de periódicos, palestras on-line, vídeo-aulas, entre outros, ampliando as fontes de divulgação e pesquisa, em formatos hipertextuais. 
Já se constatava um choque procedimental e de conhecimentos enciclopédico e genérico-textual quando os alunos universitários tinham que aprender a interagir numa nova realidade letrada. Isso ocorria, simplesmente, pela novidade/especificidade dos gêneros e assuntos apresentados na academia. Com o advento da, chamemos assim, "divulgação científica digital", somam-se a essa mudança de contexto todas as particularidades do meio virtual, com suas vantagens e problemas.

Poderíamos argumentar que as novas gerações já estão familiarizadas e frequentam os ambientes virtuais com intensidade e constância. De fato, isso ocorre. Podemos confirmá-lo com uma simples visita a shoppings ou restaurantes, onde rostos e mãos voltam-se fixamente para os celulares, lendo e enviando mensagens, por exemplo. No entanto, realizar práticas letradas mediadas por redes sociais ou por programas de correios eletrônicos não abrange toda a diversidade de funções comunicativas, contextos socioculturais, temáticas, recursos e gêneros disponíveis na rede. Portanto, defendemos que as preocupações com o desenvolvimento de aspectos do letramento no contexto acadêmico devem somar-se àquelas específicas do contexto digital. Ao fazê-lo, devem integrar os planejamentos e ações sistemáticas na universidade para a formação de seus alunos.

Toda a atividade acadêmica, quer seja de estudo, quer de pesquisa, requer, obrigatoriamente, uma etapa de revisão teórico-bibliográfica. Isso tem, em nosso meio, várias razões. Algumas que destaco são: (a) fundamenta o problema e a pesquisa que se quer desenvolver, contribuindo para sua solidez e cientificidade; (b) ajuda a delimitar caminhos, eliminando aqueles já exauridos e ajudando a aprofundar os menos explorados; (c) demonstra a erudição, capacidade de investigação e seriedade do pesquisador e (d) valoriza e reconhece que a ciência é construída por meio de trajetórias que incluem diversos pesquisadores e trabalhos. Esta é uma atividade eminentemente leitora. Requer método, cuidado, utilização de estratégias cognitivas de inferência, monitoramento, seleção, comparação e o estabelecimento de conexões com outros autores, textos e, por vezes, áreas de conhecimento. Não se trata, portanto, de uma leitura superficial ou descompromissada, como a que realizamos, muitas vezes, por lazer. Está, também, relacionada com a produção de novos textos acadêmicos, com os quais vai dialogar e, por meio dos quais, poderá deixar manifesto o próprio processo leitor prévio do sujeito. 
Consideremos que é relativamente fácil ou seguro determinar validade, pertinência e relevância de textos cujas fontes são impressas. Utilizamos as editoras e a publicação em si como aval para nossas escolhas bibliográficas. Algumas regras vêm sendo estabelecidas no próprio meio acadêmico como parâmetros adicionais para validar tais opções. São elas: a atualidade da publicação, a avaliação institucional positiva do periódico ou livro, o reconhecimento do autor no meio acadêmico e o impacto e alcance que a publicação pode ter na academia. Todos esses critérios devem ser utilizados pelo pesquisador que realiza sua revisão.

Esses parâmetros são apresentados (ou deveriam sê-lo) aos alunos universitários ao longo de sua formação e demandados, cada vez mais, à medida que o grau de titulação aumenta e os contextos de divulgação são mais prestigiosos. $\mathrm{E}$, naturalmente, valem tanto para os suportes impressos quanto para os virtuais. No entanto, a natureza fluida, efêmera, não hierárquica e multicêntrica do ambiente virtual cria algumas dificuldades para a tarefa. E, consequentemente, requer certos cuidados.

Nossa experiência docente vem mostrando-nos que, apesar de os jovens alunos estarem bastante inseridos no mundo digital, quando se veem diante da especificidade de usar a internet para fins acadêmicos, isso nem sempre ocorre de maneira tranquila. Os mecanismos de busca são subaproveitados, se desconhecem os portais de periódicos, não se usam quaisquer mecanismos de validação das fontes e conteúdos. De fato, temos observado certa surpresa entre esses alunos quando tais questões e necessidades são mencionadas. Esses aspectos de uma prática letrada específica reforçam nossa defesa de que o letramento é um estado e um conjunto de práticas em constante processo. Ou seja, não se conclui num determinado ponto da formação dos indivíduos, mas vai (ou pode ir) modificando-se, segundo as novas realidades vivenciadas envolvendo a escrita. Com base nessas constatações de ordem prática, fruto de uma vivência docente, e das características do suporte, passamos a refletir sobre os problemas da revisão bibliográfica que inclua a internet como fonte e de algumas possíveis soluções.

Gasque (2010) fala em letramento informacional, sintetizandoo como "o engajamento dos sujeitos nesse processo de aprendizagem a fim de desenvolver competências e habilidades necessárias à busca e ao uso da informação de modo eficiente e eficaz" (GASQUE, 2010, p. 
86). Destaca que, para que tal ocorra, o indivíduo deve desenvolver uma série de capacidades, a saber (GASQUE, 2010, p. 86):

-determinar a extensão das informações necessárias;

- acessar a informação de forma efetiva e eficiente;

- avaliar criticamente a informação e as suas fontes;

-incorporar a nova informação ao conhecimento prévio;

- usar a informação de forma efetiva para atingir objetivos específicos;

- compreender os aspectos econômico, legal, social do uso da informação, bem como acessá-la e usá-la ética e legalmente.

Discordamos da subdivisão do conceito de letramento (cf. tópico 1 deste artigo) e consideramos o "letramento informacional" (GASQUE, 2010) como uma das várias práticas de letramento a que estamos expostos e das que participamos ao viver numa sociedade letrada. Apesar disso, assumimos que os aspectos defendidos por Gasque para caracterizar o sujeito letrado atendem plenamente ao tópico aqui em discussão.

Para realizar uma revisão sistemática da literatura teórica sobre determinado tema em estudo, os alunos universitários necessitam primeiro estabelecer o que é pertinente e necessário ao seu trabalho. Depois, definir quais serão as fontes consultadas e usá-las de maneira adequada e eficiente, ou seja, de modo a alcançar os objetivos traçados. Uma vez definido "o que" e "de onde", cabe avaliar até que ponto as fontes são válidas e confiáveis e quais das informações ali presentes são cabíveis, tendo em vista, primeiramente, o problema. Outros critérios que devem ser levados em conta nessa avaliação são, por exemplo: atualidade, relevância, informatividade, autoria. As informações assim coletadas deverão ser trabalhadas para permitir a composição do estudo, pesquisa ou trabalho. Mas, além disso, espera-se que sejam tão pertinentes para o sujeito que ele as incorpore, igualmente, à sua bagagem de conhecimentos.

Uma questão implicada na busca de informações é o aspecto ético. Ele se reflete nos cuidados com autoria, exatidão de conteúdos, correção de dados. Em termos de prática escrita, parece lógico pensar nisso, em especial quando se remete ao tema do plágio. Mas, quando pensamos em leitura, isso também ganha relevância, pois o leitoraluno deve ser capaz de reconhecer as referências (ou a falta delas), identificar autorias, comparar conteúdos, buscando a maior precisão das informações. Atitudes conscientes e críticas no processo leitor 
podem refletir-se positivamente no posterior processo de redação dos textos do próprio aluno.

Se tais preocupações são óbvias na pesquisa bibliográfica em materiais impressos, devem ser igualmente foco de atenção naquelas realizadas em ambiente virtual. Neste caso, o cuidado com a procedência dos textos ganha especial destaque. Assim, consideramos como pautas práticas a seguir na pesquisa mediada pela internet:

a) Preferir buscadores especializados, voltados para materiais acadêmicos, ou portais de publicações acadêmico-científicas.

b) Realizar buscas utilizando parâmetros que refinem os resultados: intervalos de datas de publicação (com ênfase às mais recentes); tipo de documentos (.pdf, ou .html, por exemplo); tipo de escrito (resumos, artigos completos).

c) Uma vez encontrados os materiais nas listagens do buscador, fazer uma seleção inicial, pensando sempre no tema e problema em foco, utilizando títulos como primeiro apoio, passando, depois, para os resumos.

d) Nos artigos/resumos selecionados na primeira triagem, fazer um levantamento mais detalhado, procurando reconhecer e avaliar: autores, fonte da publicação (inclusive sua classificação), confirmação da data de publicação. Caso algum desses itens esteja ausente, pouco claro ou conflitante, há recursos que a própria internet nos fornece para esclarecimentos. 0 pesquisador pode, portanto, procurar o nome do autor na rede, ou em sites de currículos institucionais. Ali, pode verificar suas publicações, área de atuação, filiação institucional, formação. Além de garantir aspectos da autoria e fornecer ferramentas para avaliar o autor, essa prática também pode ser útil para esclarecer dúvidas quanto aos dados de publicação.

e) Uma última prática pode ser a ampliação da pesquisa, com base nas referências e bibliografias constantes nos textos selecionados. Muitas vezes os materiais podem ser encontrados na própria internet, aumentando o campo de estudo e permitindo a vinculação com autores e textos fundadores dos temas em pauta.

Consideramos que é sempre bom lembrar que a internet é uma malha intrincada de recursos e caminhos. Os materiais que buscamos para dar suporte às nossas pesquisas aparecem, muitas vezes, em diferentes locais, sob distintas formas. Em vários desses casos, há informações destoantes, como: diferentes datas, ausência ou incompletude de lugar de publicação, falta do nome do autor. 0 pesquisador tem 
que saber lidar com essas circunstâncias, comparando o que encontra entre si, sempre que as dúvidas apareçam.

Outro aspecto refere-se à efemeridade própria do meio virtual. 0 fato de encontrar certos materiais numa época não garante que estejam no mesmo lugar, ou mesmo continuem disponíveis num futuro. Por isso, o cuidado em armazenar textos de interesse, catalogando-os, é vital para garantir a posse dos recursos. Nunca se deve esquecer, também, de anotar as datas de acesso e os sites, o que contribui para sua confiabilidade e um possível resgate posterior por outros pesquisadores, quando usados tais textos e bibliografias como referências.

Por fim, destacamos como parte do processo leitor com objetivos de revisão teórico-metodológica a necessidade de integração de conteúdos. Uma leitura eficiente e plena para fins de estudo e pesquisa acadêmicos envolve lidar com a pluralidade de vozes que circulam na academia. E tais vozes não funcionam em uníssono: há múltiplas correntes e orientações que precisam ser comparadas, contrastadas, por vezes postas em oposição, por outras, conciliadas. Trata-se de um trabalho complexo, que demanda conhecimentos sobre os temas em pauta, observação, análise e criticidade.

Esta tarefa pode tornar-se mais complexa se as fontes forem virtuais, devido a todos os pontos discutidos anteriormente. Muitas vezes os textos estão dispersos e misturados. Não estão, como em uma biblioteca, por exemplo, organizados por temática ou autor. Essa organização, bem como a identificação e categorização de suas distintas propostas teórico-metodológicas cabem exclusiva e prioritariamente ao leitor. Ele possui virtualmente uma infinidade de recursos ao alcance de alguns clics. Mas, ao mesmo tempo, precisa desenvolver uma mecânica de trabalho que contemple a profunda seleção, avaliação, comparação e organização de todo esse acervo. Não é uma atividade intuitiva ou simples. Requer disciplina, sistemática, capacidade de observação e crítica, que ocorre e se aperfeiçoa tanto por aprendizado, quanto pelo próprio exercício.

\section{Um cenário teórico e prático em mudança e construção: conclusões em processo}

A pesquisa e as diversas tarefas do meio acadêmico-científico constituem práticas letradas. São específicas deste contexto e compartilhadas pelos indivíduos que nele circulam. No entanto, como 
ocorre com qualquer prática de letramento, oferecem uma novidade a ser entendida, aprendida e incorporada pelos membros mais novos da comunidade: os estudantes universitários nos diferentes níveis. Por isso, defendemos a importância de incluir propostas didáticopedagógicas e conteúdos voltados para as suas especificidades nos currículos universitários.

A grande parte do fazer acadêmico está intimamente ligada ao trabalho de revisão teórico-metodológica. Hoje, a internet se apresenta como o suporte por excelência para buscas abrangentes e ágeis. 0 problema é que o meio virtual possui características que muitas vezes não garantem a confiabilidade das fontes e conteúdos. Devido a isso, a tudo o que se considera relevante para a atividade de estudo e revisão bibliográfica é preciso somar cuidados derivados especificamente da estrutura do meio. 0 fato de os alunos serem usuários assíduos dos ambientes virtuais não garante, de forma plena, sua capacidade de realizar tarefas mediadas pela letra escrita com fins acadêmicos nesses contextos. Portanto, cabe levá-lo em consideração também no processo de desenvolvimento do letramento desses sujeitos.

Embora tudo o que discutimos possa parecer óbvio, considerando o conceito que todos compartilhamos sobre $o$ ambiente acadêmico, não vemos na prática uma inclusão das pautas que propusemos no tópico anterior de maneira efetiva e generalizada. No que se refere à internet, essa limitação nas reflexões formais e sistemáticas sobre letramento no ambiente universitário nos parece ainda mais patente. Talvez tenhamos que admitir que vivemos um momento de transição. Coexistem gerações que foram formadas nos modelos pré-digitais com as que estão imersas no boom das tecnologias da informação e comunicação em termos cotidianos. A própria internet e as TICs estão em constante mudança, o que imprime ao contexto atual certo grau de incerteza.

No entanto, parece-nos, e defendemos tal posição, que não é a geração o fator decisivo neste caso. Os usos da internet, assim como as práticas letradas, são diferenciados segundo cada situação. Isso significa que, mesmo sem terem sido preparados para lidar com as TICs, os professores universitários podem desenvolver, com base nos seus conhecimentos prévios e nos níveis de letramento que possuem, estratégias compensatórias. Portanto, podem ser orientadores de seus alunos na construção de um degrau a mais em seu letramento. Neste processo, ambos podem incorporar habilidades e estratégias que os ajudem a lidar com as práticas letradas acadêmicas mediadas pelas TICs. 
Seja como for, consideramos que o diálogo e a troca podem ser formas eficazes de favorecer ambos os perfis de sujeitos: professores e alunos. Também cremos que todo o cenário, seja em termos teóricos, seja na prática metodológica, está, como o próprio ambiente virtual, em estado de construção e mudança. Olhamos e teorizamos sobre o fenômeno desde seu interior. Isso significa que serão os próximos anos que permitirão consolidar ou reavaliar e modificar conhecimentos e práticas a respeito do tema.

\section{ABSTRACT}

In this paper we present theoretical insights about the literacy practice of bibliographic review by undergraduate and graduate students, thought as a kind of reading comprehension. Our focus is on the implications of the Internet as a source for research and its relations with the literacy development. We also propose some parameters for improving this literacy activity. We follow the works of Cerutti-Rizzatti, Kleiman, Gasque e Soares on the concept of literacy; however, we reject the plural form of the term. For the reading comprehension background, we use the Vergnano-Junger's multidirectional perspective. We advocate that literacy activities in the university setting challenge the students and demand specific learning processes that must be included in the academic curricula. The Internet is an important resource for carrying on researches and bibliographic reviews. Nevertheless, because of the virtual environment characteristics, these activities demand the ability to selecting, comparing, organizing, and criticizing that adds up to other abilities, strategies and knowledge already required by printed materials. We acknowledge that this systematic approach to reading comprehension and bibliographic review is seldom regarded in the academic curricula. Furthermore, it is even more rare the Internet to be regarded as a resource. Finally, we conclude that this reality is probably related to the transition moment that we live in regards to our relations with the information and communication technology and the practices that they establish. 
KEY-WORDS: literacy; bibliographic review; Internet

\section{REFERÊNCIAS}

BACHER, S. Tatuados por los medios: dilemas de la educación en la era digital. Buenos Aires: Paidós, 2009.

CASSANY, D. En_línea: leer y escribir en la red. Barcelona: Anagrama, 2012. CASTELA, G. da S. formação e atuação do docente de língua estrangeira: um enfoque no letramento digital. Educere et Educare, Cascavel, v. 3, n. 5, jan. jun., 2008, p. 167-173.

CERUTTI-RIZZATTI, M. E. Letramento: uma discussão sobre implicações de fronteiras conceituais. Educação e Sociedade, Campinas, v. 33, n. 118, jan.mar., 2012, p. 291-305.

CUBO DE SEVERINO, L. CASTRO DE CASTILLO, E. Introducción. In: CUBO DE SEVERINO, L. (coord.) Los textos de la ciencia: principales clases del discurso académico-científico. Córdoba: Comunic-arte, 2005. p. 15-20.

GASQUE, K. C. G. D. Arcabouço conceitual do letramento informacional. Ciência da Informação, Brasília, v. 39, n. 3, set./dez., 2010, p. 83-92.

GUTIÉRREZ RODILLA, Bertha. El lenguaje de las ciencias. Madrid: Gredos, 2005. KLEIMAN, A. Leitura: ensino e pesquisa. 2 ed. Campinas: Pontes, 1996.

. Modelos de letramento e as práticas de alfabetização na escola. IN:KLEIMAN, A. (Org.) Os significados do letramento: uma nova perspectiva sobre a prática social da escrita. 7a. reimp. Campinas: Mercado de Letras, 2004. p. 15-61.

. Trajetórias de acesso ao mundo da escrita: relevância das práticas não escolares de letramento para o letramento escolar. Perspectiva, Florianópolis, v. 28, n. 2, jul./dez, 2010, p. 375-400.

LAVID, J. Lenguaje y nuevas tecnologías: nuevas perspectivas, métodos y herramientas para el lingüista del siglo XXI. Madrid: Cátedra, 2005.

MARCUSCHI, L. A. Produção textual, análise de gêneros e compreensão. $5^{a}$ reimp. São Paulo: Parábola, 2008.

MENDOZA, J. El canon digital: la escuela y los libros en la cibercultura. Buenos Aires: La Crujía, 2011.

NUNES, Myriam Brito Corrêa. Visão Sócio-interacional de Leitura. Oficina de Leitura Instrumental: Planejamento e Elaboração de Materiais; coletânea de documentos. Rio de Janeiro: IPEL/PUC-Rio, 2005.[Artigo 02; publicação em CD-ROM] 
PERFETTI, C.A. LANDI, N. OAKHILL, J. A aquisição da habilidade de compreensão da leitura. IN:SNOWLING, M. J. HULME, C. (Orgs.) A ciência da leitura. Porto Alegre: Penso, 2013. p. 245-265.

ROJO, R. Letramentos múltiplos, escola e inclusão social. São Paulo: Parábola Editorial, 2009.

SOARES, M. Novas práticas de leitura e escrita: letramento na cibercultura. Educação e Sociedade, Campinas, v. 23, n. 81, dez., 2002, p. 143-160.

VERGNANO-JUNGER, Cristina. Leitura na sociedade da informação e formação de professores: um olhar sociocognitivo. In: Linguagem: Teoria, Análise e Aplicações, v. 8. [meio digital]. Rio de Janeiro: Programa de Pós-graduação em Letras/ UERJ, 2015 (fase final de editoração).

\section{NOTAS}

${ }^{1}$ Tradução livre da autora: "cultura letrada, cultura industrial e cibercultura participam de uma emulsão intercultural sem precedentes”.

2 Tradução livre da autora: internet "emerge [...] como novos caminhos de circulação da cultura industrial [...]; mas também como suporte de recontextualização da cultura letrada [...]"

${ }^{3}$ Ao longo deste artigo, utilizamos os termos "leitura", "processo leitor", “compreensão" (leitora) e correlatos com sentidos equivalentes, para nos referirmos à leitura, entendida como expomos, em especial, no tópico 3. Embora apresentemos diferentes modelos de leitura, seguimos uma perspectiva multidirecional (cf. tópico 3 deste artigo) para embasar nossas reflexões. ${ }^{4}$ Conforme aparece esclarecido no artigo citado, tal posicionamento teóricometodológico, tem seu ponto de partida, primeiramente, nas considerações de Marcuschi sobre o tema dos gêneros textuais ao longo de diversos de seus estudos. Em seguida, dialoga com a pesquisa desenvolvida por Donato em seu mestrado, em 2014.

Recebido em: 30 de abril de 2015.

Aceito em: 10 de maio de 2015. 